Thefollowing paper received the first place, under the category of under 35 years of age at the "IWMI competition" 2002 sponsored by the

International Water Management Institute

\title{
* Minimum Information Requirement Modelling for * Catchment Water Resource Management
}

\author{
N. D. K. Dayawansa
}

Abstrar I: Pollution of surface and sub surface water from agricultural nutrients; especially from nitiogen and phosphorus is a widespread environmental problem. Mathematical models play a substantial role in predicting and forecasting hydrological and water quality related issues at different spatial scales. A need of an easily calibratable and minimum information requirement models to be used in predictions at catchment scale and subsequent policy formulation and management was identified in this study. The existed TOPCAT-N model was further developed to add a phosphorus component and efficient model-user interface and was named TOPCAT-NP. To study the model applicability to tropical monsoon rtlli'i ted climatic conditions, field sampling was carried out at upper Uma Oya catchment and its few land use specific sub catchments in central Sri Lanka for a nine month period. Hydrochemical assessment and TOPCAT-NP modelling were performed with collected data. Effect of land use scenarios and the model and parameter uncertainty were also assessed.

The TOPCAT-NP predicts flow, nitrate nitrogen, soluble and sediment attached phosphorus at the catchment scale with a relatively few key input parameters. The model stands between complex physically based models such as EPIC and simple catchment scale empirical models such as export coefficient approar h. TOPCAT-NP simulates the flow and nutrients at daily or sub daily time steps provided that irtinliilland evapotranspiration are input. Improved temporal resolution of the output provides seasonal $<$ hanges in nutrient mobility for better implementation of management strategies at correct time and place.

I I he hydro-chemical assessment in upper Uma Oya suggests that there is no great threat to the surface $\mathrm{u}$ atef Irom nutrients though, ground water contains very high levels of nitrates in agricultural areas. The farmers continue to apply over doses of fertiliser to the agricultural fields. Land use mainly agriculture has a prominent effect on surface and ground water nutrient levels. Nutrient release from the land to itream is mainly governed by the storm events. Increasing levels of stream and soil matrix nitrate was observed following storm events. TOPCAT-NP reasonably simulates the flow and nitrate patterns I " in ever, the behaviour of $\mathrm{P}$ is highly unpredictable. Land use effect is highly visible in scenario analysis and II also provides guidance to the uncertainty in the predictions. If the rainfall intensity could be in luded and a direct link to GIS can be established, the model predictions may improve substantially to bi used in catchment management aspects.

\section{Introduction}

Monitoring, measuring and modelling of the Guintiti and quality of water have become a majot concern to environmentalists in both developed and developing countries in recent times. Water quality data have been collected and models have been developed at various spatial rttul temporal scales to simulate and predict the pollutant transport behaviour in the terrestrial and hydrological systems. Surface and ground water contamination due to agricultural nutrients is constantly reported in intensive farming systems. In general, nutrient data are gathered at a local 'plot' scale or in lysimeter studies, but it is oftenthe transport behaviour of pollutants that is critically important in downstream problems. Plant nutrients leave the land through surface and sub surface hydrological pathways and thus enter the water system and ultimately trigger aquatic plant growth. Undesirable growth of aquatic plants can cause eutrophic conditions in water

$\operatorname{Dr}($ Ms) N.D.K. Dayawansa. B.Sc. (Agric)(Peradeniya),M.Sc: (AIT), Ph.D. (Newcastle upon Tyne, UK)

Senior Lecturer, Department of Agricultural Engineering, Faculty of Agriculture, UniversityofPeradeniya, Sri Lanka 
making it unsuitable for use by humans and animals.Tracing the local cause and the downstream impact has drawn less emphasis, however, it is this scaling up component that is critical in view of setting strategies for catchment management.

Water quality research has not drawn much attention in Sri Lanka due to the fact that no serious water quality problems have been encountered, probably due to the abundance of natural water resources in the country. However, this situation has been rapidly changing over the last decade. High population growth rate and subsequent pressure on the land have created water related problems in major river catchments in the country. Further, nutrient transport studies in monsoon affected mountain regions have received less attention compared to soil erosion and sedimentation studies. Water quantity measurements are carried out in selected rivers on daily or sub daily intervals mainly for the purpose of irrigation though continuous quality measurements have had little consideration.

\subsection{Nutrient Pollution}

Over exploitation of land resources for agriculture is the direct result of ever increasing population growth, which creates a high demand for food. An estimated land extent of $8.5 \times 10^{8}$ has been converted to agricultural land globally over the past 100 years (Vinten \& Smith, 1993). The green revolution in early 1970's promoted the widespread use of agricultural inputs such as fertiliser and agro-chemicals to obtain higher yields. The world-wide use of fertiliser is rising steadily. However, the pattern of use within individual countries varies widely due to a variety of factors including population growth rate, the extent of the development of agricultural technology and the concerns over the purity of potable water. Continuous fall in fertiliser prices in the competitive market and government subsidies have also stimulated the over-use of fertiliser. Leagreid et al. (1999) stated that Asia uses much more fertiliser than that of Africa and South America and is biased towards excess N application compared to $\mathrm{P}$ and Potassium (K).

Water quality deterioration is partly an environmental problem associated with agriculture, which affects human, animal and plant health. Sediments, agro-chemicals and fertilisers from agricultural fields can adversely affect the quality of surface and sub-surface water. Rising concerns over sustainable agriculture indicate that the modern agricultural activities have a great responsibility of generating point and non point sources of water pollutants and creating surface water eutrophication. Among the plant nutrients, $\mathrm{N} \& \mathrm{P}$ are the mostly responsible nutrients in terms of water pollution. There is currently a special concern on water pollution by nitrate $\left(\mathrm{NO}_{3}\right)$ since it poses a great threat on human and animal health (Greenwood \& Walker, 1990). N and P together can create eutrophic conditions in fresh water.

\subsection{Objectives}

The main objective of this paper is to discuss the importance of Minimum Information Requirement (MIR) modelling for catchment management in the situations where a comprehensive collection of catchment information is not adequately available. It also intends to discuss a MIR model called TOPCAT$\mathrm{NP}$ and its application to a selected agricultural catchment in Sri Lanka to simulate the flow, nutrients (NO3-N \& P) and to identify the impact of different land use scenarios on stream water quantity and quality.

\section{MIR Modelling}

The Minimum Information Requirement (MIR) approach for catchment scale modelling is a novel conceptputforward by Anthony et al. (1996). MIR models are basically the functional representations of complex physically-based models and rely on few key parameters which are sensitive to the spatiotemporal variability. The characteristic features of the models are the simple model configuration, a minimum information requirement and a high functionality combined with the capability of mimicking the results of a complex physically-based model. This concept attempts to minimise the parameter-related uncertainty by keeping the number of parameters to a minimum and to reflect areas of uncertainty in a clear way. The question of catchment heterogeneity is addressed within the MIR framework by simple statistical representation of the model parameters. TOPCAT-N (Anthony et al., 1996, Quinn et al., 1996,1999) is the first model to be developed based on MIR approach to simulate the river flow and $\mathrm{NO}_{3}$ loss at the 


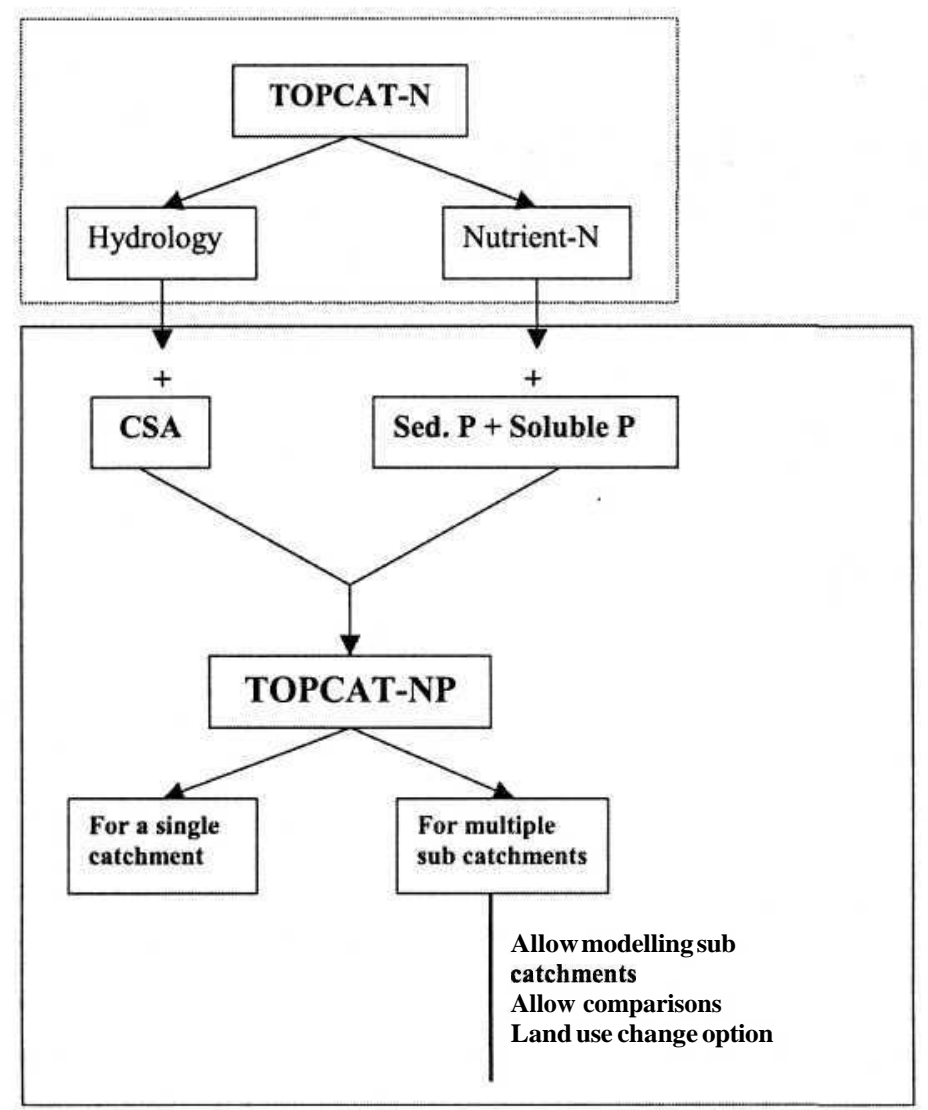

Figure 01: The steps in TOPCAT-NP development.

ath hment scale. TOPCAT-N shares a number of II IPMODEL(Quinn \& Beven, 1993)hydrological . pts and also consists of an empirical lear-hing equation derived by mimicking the eutput of one-dimensional Solute Leaching Intermediate Model (SLIM) (Addiscott \& Whitmore, 1991). This paper discusses a MIR model allied TOPCAT-NP which includes hydrology, NO3-N and P components.

\subsection{TOPCAT-NP MIR Model}

TIPCAT-NP is a simple MIR model that can ilmulate the hydrology, NO3-N and soluble \& sediment attached $\mathrm{P}$ transport at the catchment sale The model uses the hydrology and nutrient transport components of TOPCAT-N (Anthony et al. 1996، Quinn et al., 1996,1999) with the influsion of critical source area contributions. The basic concepts of EPIC (Williams, 1995) physically based model and simple export coefficient approach (Johnes \& O'Sullivan, 1989; Beaulac \& Rerkhow، 1982; Johnes, 1996; Johnes et al., 1996) were used in developing the model. The model generates the flow and $\mathrm{NO}_{3}-\mathrm{N}$ at any time step. The Ptransport component consists of soluble $\mathrm{P}$ and sediment attached $\mathrm{P}$ transport within the catchment. The amount of soil loss per unit runoff and unit width of hillslope was taken from another MIR model called MIRSED (Brazier et al., 2001) for the purpose of calculating the sediment attached P. The steps involved in TOPCAT-NP development is presented in Figure 01.

The TOPCAT-NP compiled on a EXCEL spreadsheet and the output of the model can be obtained in tabular or graphical form. Model works on daily or sub-daily time steps and rainfall, flow and evapotranspiration data are needed as input. Flow, $\mathrm{NO}_{3}-\mathrm{N}$, soluble $\mathrm{PO}_{4}$ and sediment attached $\mathrm{P}$ are the output of TOPCATNP. The graphical output and the interactive calibration buttons attached to the parameters are centrally located in the EXCEL worksheet with the model structure (Figure 02). The TOPCAT-NP consists of only 14 calibration parameters. The interactive parameter buttons are usefulto change the parameter values within a realistic range to obtain a proper calibration. The output graphs located adjacent to the buttons immediately reflect the model response to parameter change. This facilitates easier and fast calibration and the 


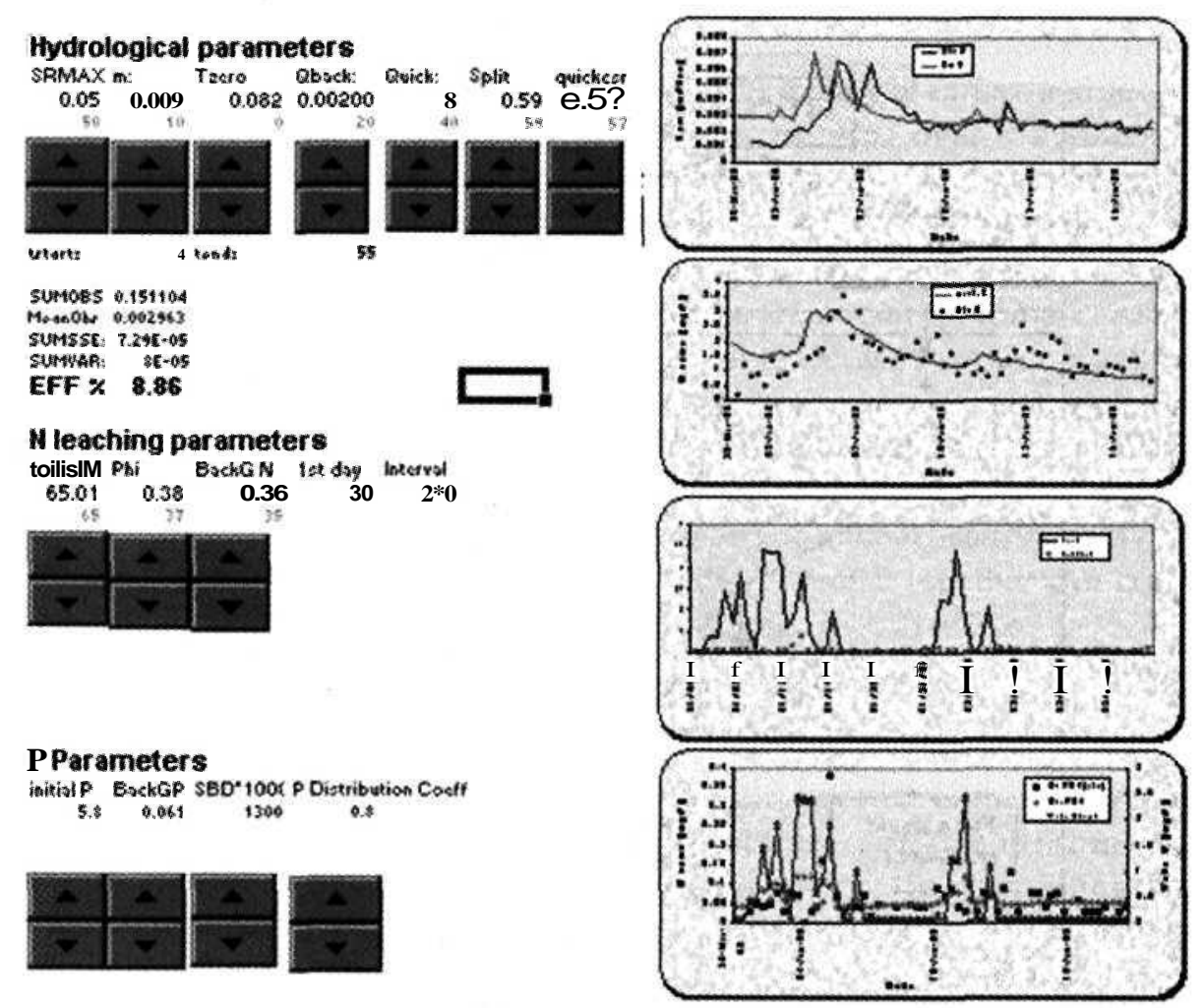

Figure 02: TOPCAT-NP interactive calibration buttons and the model output.

uncertainty in the output due to parameters are also directly visible. TOPCAT-NP which allows multiple catchment simulation is considered as an appropriate tool to compare the performances of the catchments.

\subsection{Relevance of MIR Modelling ApproachtoSriLankan Conditions}

Sri Lanka is a developing country where a large proportion of land is converted to agriculture annually. Most of these agricultural lands are in the hill country where the slopes are steep and very erosive rains occur. Sri Lanka has a radial pattern of stream network and a large number of streams originate from the central highlands. Therefore, there is an obvious threat to the aquatic resources in this area due to agriculture and related activities. Nevertheless, the environmental impact assessments have been only limited to major projects and no assessments have been carried out on small scale land use conversions to agriculture. In this regard, simple catchment management tools such as MIR models have a great potential to identify and predict the existing and future problems of stream quality with relativelylittleavailableinformation.

\section{Application of TOPCAT-NP to Upper Uma Oya}

It is important to study the applicability of TOPCAT-NP model to Sri Lankan conditions. Accordingly, the model was applied to Upper Uma Oya catchment in the central highlands of Sri Lanka. In view of this, a nine-month long field campaign was carried out to collect $\mathrm{NO}_{3}-\mathrm{N}$ and $\mathrm{P}$ data at eight sampling sites at weekly intervals. The sampling sites represented the major land use/covertypes of natural forest, tea, agriculture and mixed land use in the study area. A sub daily sampling of flow and nutrients was carried out at Sandatenna agriculture dominated sub catchment forfourweeks to study the storm effect on nutrient mobility. The relevant flow, rainfall and evapo-transpiration data were also collected.

\subsection{Upper Uma Oya Catchment}

Uma Oya is a main tributary of the Mahaweli river and is the only main stream draining into Rantembe reservoir; the last of the chain of reservoirs constructed under the Accelerated Mahaweli Development Program (AMDP). The total land extent of Uma Oya catchment is 740 $\mathrm{km}^{2}$ and it starts from Nuwara Eliya and extends 
up-to Rantembe area. The Upper Uma Oya catchment consists of the area above the gauging station at Welimada, which is maintained by the Mahaweli Authority of Sri Lanka. The total aerial extent of Upper Uma Oya is $94.5 \mathrm{~km}^{2}$ and extends from Nuwara Eliya to Welimada.

Uma Oya flows through natural cloud forests as well as highly intensive agricultural lands in both Nuwara Eliya and Welimada and therefore, has been identified as an ideal stream to investigate the nutrient transport behaviour of different land use/cover systems. It has also reported the highest sediment generation rate compared to some other sub catchments within the Upper Mahaweli Catchment Area (UMCA) (Yatawara, 1996). Due to high monsoonal input, the dilution of nutrients in streams keeps the concentrations low. However, localised and sporadic eutrophication problems are often being seen. The threat of more eutrophication is clear due to rapid land use conversion and more input of fertiliser. It is important to identify the threshold limit of fertiliser use to keep the $\mathrm{NO}_{3}-\mathrm{N}$ and $\mathrm{P}$ levels in surface and ground water forlongterm sustainability. The location of UMCA and Upper Uma Oya catchments are presented in Figure 03.

\subsection{General Water Quality Assessment of Upper Uma Oya}

The rainfallrecords of SeethaEliya and Welimada gauging stations from 1994 to 2000 produce a clear contrast in rainfall in headwater and downstream areas. The average annual rainfall at Seetha Eliya station of the upper catchment region is 2280 $\mathrm{mm} / \mathrm{yr}$, while it is $1343 \mathrm{~mm} / \mathrm{yr}$ at the Welimada station at the outlet. Basic water quality statistics of the eight sampling sites is presented in Figure 04. According to the statistics, vegetable sites produce relatively higher mean and median concentrations of $\mathrm{NO}_{3}-\mathrm{N}, \mathrm{PO}_{4}$, and TDS. The site variations of the concentrations are also observed. The mean concentrations of $\mathrm{NO}_{3}-\mathrm{N}$ and $\mathrm{PO}_{4}$ at the Uma Oya sub catchment outlet are 1.952 and $0.6 \mathrm{mg} / 1$ respectively. None of the sampling sites exceeds the recommended WHO concentration of $10 \mathrm{mg} / 1$. However, the soluble $\mathrm{PO}_{4}$ concentrations always exceed the recommended limit of $0.1 \mathrm{mg} / 1$ stipulated by USEPA (1986). Forests have the lowest and consistent concentrations of measured parameters. The higher standard deviations which indicate high fluctuations in concentrations in vegetable and mixed land use/cover sites can be due to the fluctuations in point and non-point discharges according to the changing climatic conditions.

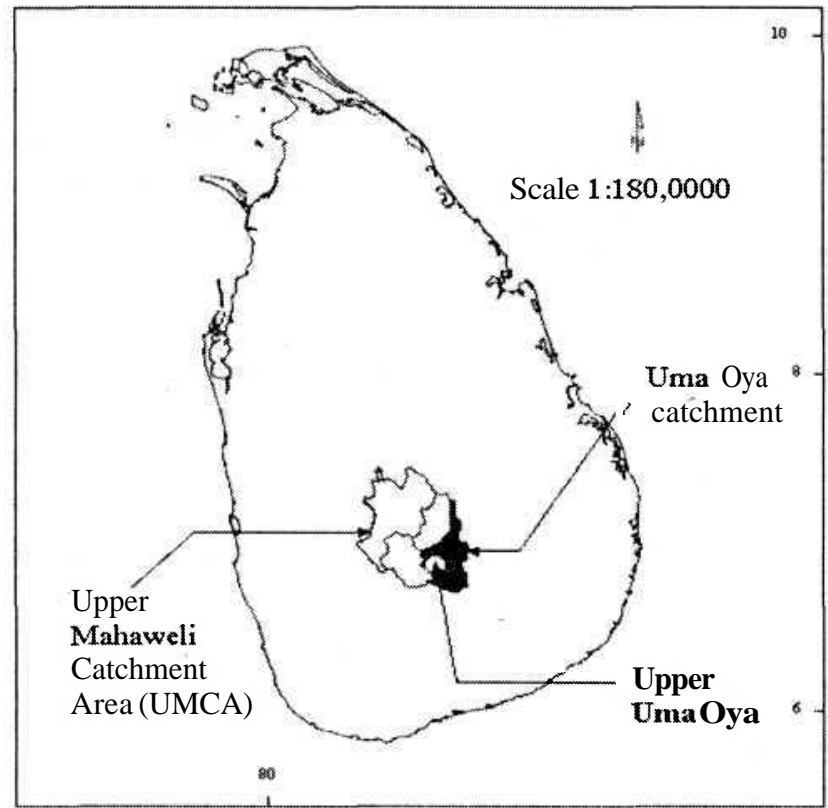

Figure 03: Location of Upper Uma Oya within the UMCA. 


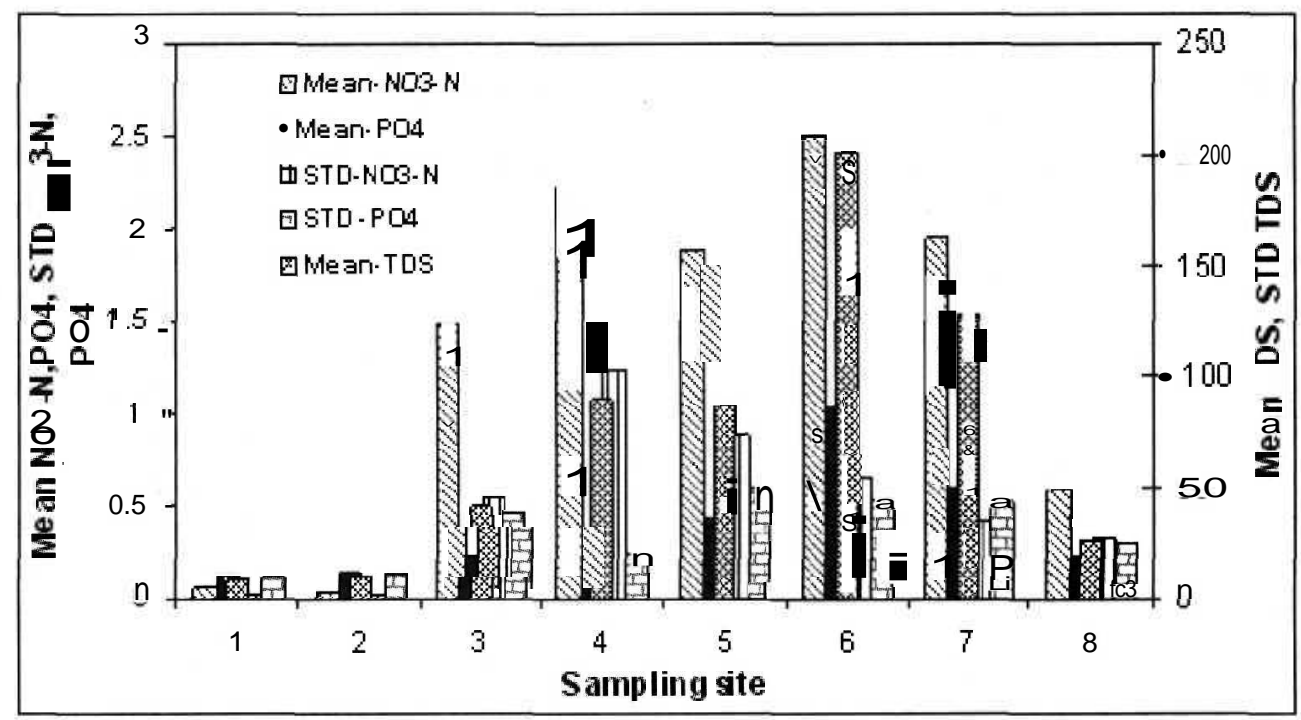

Figure 04: General water quality statistics of Upper Uma Oya.

According to the statistical assessment of sampled nutrient data to identify the land use and spatial effect on surface water quality revealed that there is a significant effect between water quality and the land use. The spatial effect is also significant within the same land use/cover class except for forests. The vegetables contribute greatly to the surface and sub surface (well) water quality in the catchment. Though, tea receives a substantial quantity of inorganic fertiliser, the contribution of tea towards water quality is significantly minimum. Forest is the lowest contributing land use class according to the sampled data.

\subsection{Hydrological and Water Quality Modelling}

The unavailability of adequate catchment information on hydrology, water quality and soil nutrient status were the main limitations in applying complex physically based models to simulate catchment dynamics.. In this particular case also, information for the Upper Uma Oya catchment was very limited hence, the application of a MIR model was the feasible option. In hydrological and watre quality modelling, the entire Upper Uma Oya catchment and a small agriculture dominated sub catchment called Sandatenna, near Nuwara Eliya, were modelled for flow and nutrients. The model can closely simulate the observed pattern of flow at Upper Uma Oya catchment outlet (Figure 05). It is apparent that the model efficiency improves with the wetting up of the catchment. The major hydrograph peaks during the rainy season and produces an excellent agreement with those of the measured. The model overestimates the flow during the 98/99 rainy season. In this season, the volume of water in the system is relatively low. Storm flow largely dominates the stream flow and therefore, individual storm events produce a sharp recession immediately after the rainfall events.

Figure 06 shows the pattern of $\mathrm{NO}_{3}-\mathrm{N}$ transport in the catchment from March, 2000 to August 2000. In the modelling results from January, 1996 to August, 2000 period, the annual $\mathrm{NO}_{3}-\mathrm{N}$ leaching cycles were prominent, however, different leaching rates were observed. The sharp downward peaks occur due to dilution of $\mathrm{NO}_{3}$ $\mathrm{N}$. According to the Figure 06, the recession of $\mathrm{NO}_{3}-\mathrm{N}$ with the recession limb of the annual flow hydrograph is very prominent. The outcome of the P modelling is presented in Figure 07. Sudden peaks in observed $\mathrm{PO}_{4}$ may be a result of localised events such as point source discharges. The farmers in the lower region of the catchment irrigate their rice and vegetable fields with stream water and redirect the excess water back to the stream. Usually, this water is extremely sediment rich and could be equally high in $\mathrm{P}$ as the sediment is derived from $\mathrm{P}$ rich soils. This also could be a reason for suddenly elevated soluble $\mathrm{PO}_{4}$ in stream water. Since, leaching is an equally important phenomenon for P in Upper Uma Oya catchment due to $\mathrm{P}$ saturated soils, the stream $\mathrm{P}$ levels seem to be linked with the 'event' discharge 


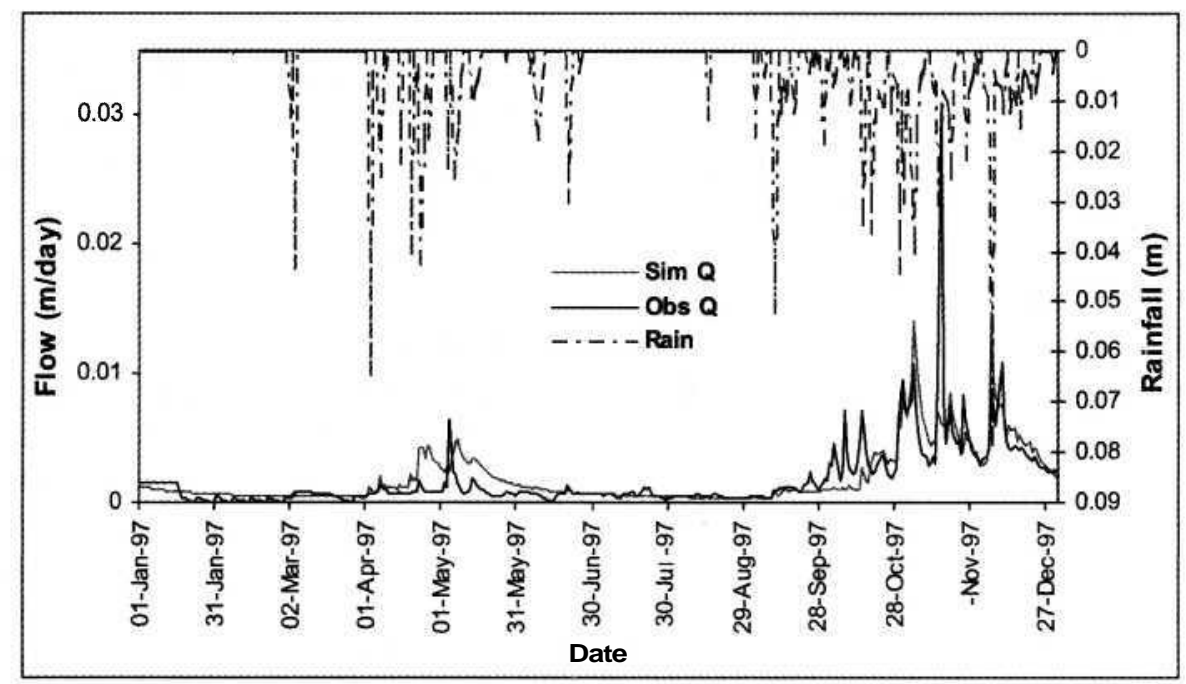

Figure 05: Rainfall, simulated and observed flow hydrographs for calibration. period at Welimada gauging station (Jan 1997-Dec. 1997).

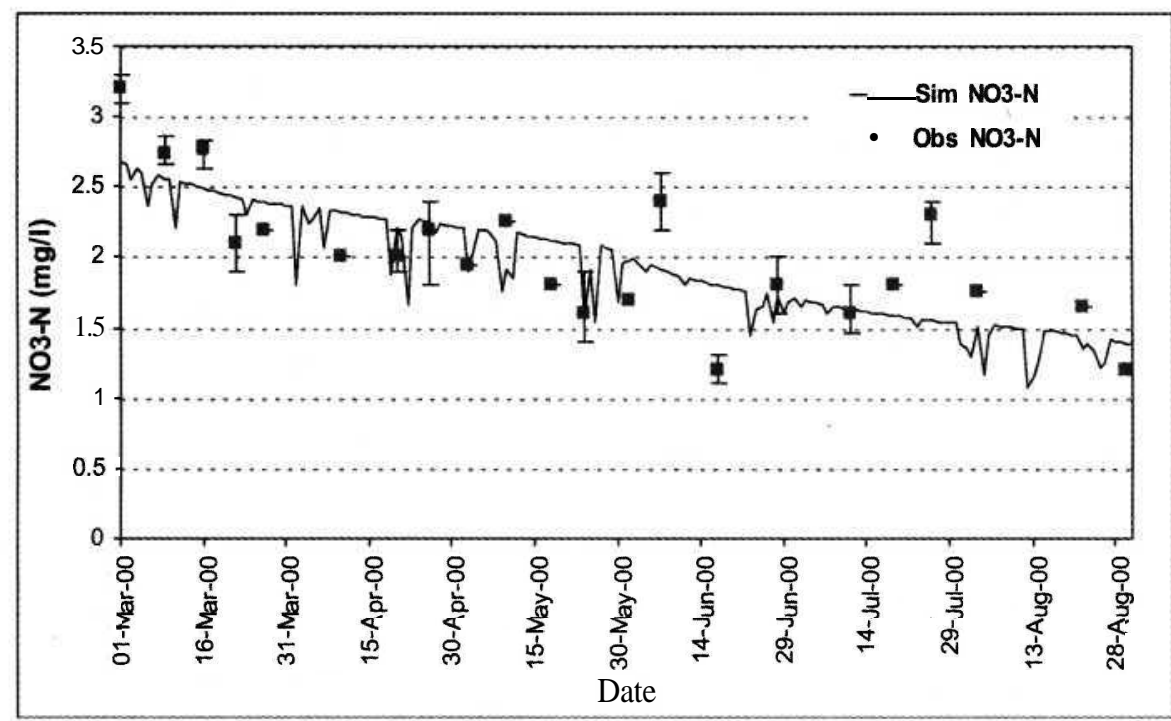

Figure 06: Calibration result of $\mathrm{NO}_{3}$ module at gauging station (Jan-Aug, 2000).

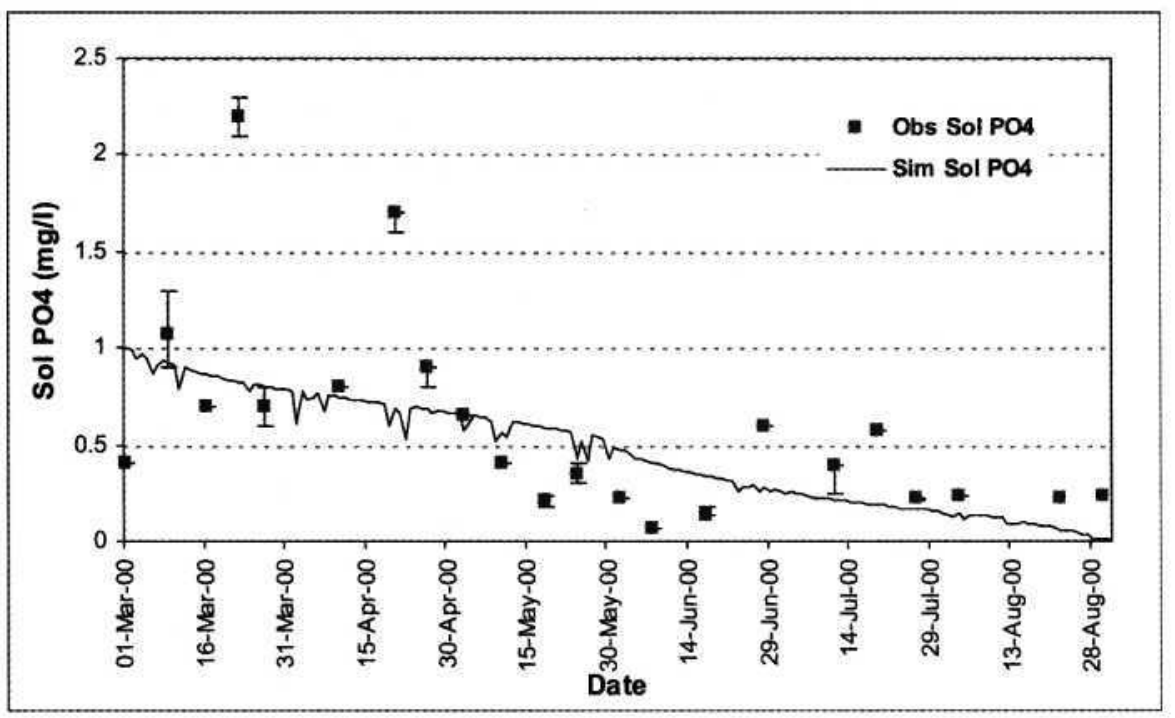

Figure 07: Observed and simulated soluble $\mathbf{P O}_{4}$ after independent calibration of P module (Jan.- Aug.2000). 
The modelling results at the Sandatenna site revealed the importance of the availability of accurate flow records and data of high intensity. The flow was approximated using velocity area method at Sandatenna and the daily rainfall records had to be fragmented to obtain sub daily rainfall. The sub daily data of the catchment provide a good simulation of flow and nutrients. However, due to inadequate rainfall records the peaks of the measured flow and nutrients do not coinside with that of the measured. The results suggest the need for the rainfall and evapotranspiration records at the required time steps for modelling.

In the land use scenario analysis, four land use/ cover types have been selected to best represent the past, current and possible future land use/ cover transformations that can occur in the study area. The land use/cover has been transformed from natural forestcover to plantation agriculture; mainly tea during the British colonial period (Wickramagamage, 1998). The 100\% forest and $100 \%$ tea scenarios represent the past catchment conditions which reflect the stream quality characteristics when the catchment was less disturbed.

The stream $\mathrm{NO}_{3}$ and $\mathrm{P}$ levels are highly sensitive to agricultural land use. According to the model predictions, even if the catchment is entirely converted to agriculture, the stream $\mathrm{NO}_{3}-\mathrm{N}$ level does not exceed the WHO drinking limit of $10 \mathrm{mg} / 1$.. Given the uncertainty, this value could be well above the recommended limit. Generally, the stream $\mathrm{PO}_{4}$ exceeds the levels to cause eutrophic conditions $(0.01 \mathrm{mg} / 1$ dissolved $\mathrm{P} \&$ 0.02 total $\mathrm{P}$ ) even with the natural forest conditions. Nitrogen may act as the limiting nutrient as there is no apparent eutrophication threat even in the agricultural catchments at present. The average concentrations of $\mathrm{NO}_{3}-\mathrm{N}$, soluble $\mathrm{PO}_{4}$ and total $\mathrm{P}$ in $\mathrm{mg} / 1$ under four land use/cover categories change according to the following sequence.

- Agriculture (6.6355)> Mixed (2.664)> Tea (0.763)> Forest (0.0855) $-\mathrm{NO}_{3}-\mathrm{N}$

- Agriculture (2.0658)> Mixed (1.8862)> Forest $(0.1225)>$ Tea $(0.0638)$ - Sol. $\mathrm{PO}_{4}$

- Agriculture (0.7473)> Mixed (0.5519)> Forest (0.2092)> Tea (0.1518) - Total P
The direct results of the modelled scenarios suggest the possibility of further conversion of catchment land to agriculture while keeping the stream $\mathrm{NO}_{3}-\mathrm{N}$ level at admissible limit. This is further supported by the lack of evidence for eutrophication, even with very high $\mathrm{P}$ levels. However, the model forecasts should not be solely considered for recommendations, as an integration of factors may decide the ultimate nutrient content in streams. Land use/cover scenario analysis reveals the inherent uncertainty associated with these parameters. Initial $\mathrm{N}$ and $\mathrm{P}$ levels are the mostly sensitive parameters and obtaining representative effective values for the entire catchment will always be associated with a high degree of uncertainty. Landscape heterogeneity plays a great role in nutrient distribution making it hard to upscale the soil test $\mathrm{N}$ and $\mathrm{P}$ values estimated for a small sub catchment. Field scale variability may be caused by fertiliser distribution or movement within the field while farm scale variability occurs due to distance to road or manure storage facilities (Needelman etal., 2001). Natural factors such as weathering conditions, soil parental material, erosion and water movement pattern can influence soil $\mathrm{P}$ distribution. The agricultural catchments located at the headwater region of the Upper Uma Oya, exhibit significant climatic and land management differences compared to the lower region. Therefore, generalisation of the modelling results for land use/cover management planning would need great care. The high soluble and total $\mathrm{P}$ levels under all four land use/cover imply the necessity of interactive management strategies for these two nutrients (Heathwaite et al., 2000). Although, the 100\% agriculture scenario does not exceed the recommended stream $\mathrm{NO}_{3}-\mathrm{N}$ levels (with the calibrated parameters), together with increasing $P$ level it can stimulate eutrophic conditions in the streams and open water bodies. However, this model does not address the possible deep groundwater contamination of $\mathrm{NO}_{3}$. The measured well water at Sandatenna agricultural catchment produced extremely high $\mathrm{NO}_{3}-\mathrm{N}$ values. According to the observations, ground water contamination is inevitable under agriculture. These high $\mathrm{NO}_{3}$ levels may appear in background flow of the streams and may elevate the stream $\mathrm{NO}_{3}-\mathrm{N}$ levels above the recommended concentrations. Almost all the suitable lands are under subsistence agriculture 
in the area. If the catchment is entirely under agriculture, conversion of unsuitable slopes to arable lands is unavoidable. This will aggravate the existing soil erosion problem (Rajapakse, 1998) and will also lead to generate new critical source areas. Therefore, the ultimate effects may be more serious compared to the forecasted stream quality status. On the other hand, other environmental problems, such as siltation of reservoirs and heavy metal pollution, which are not addressed by this model can appear along with the land use changes. Further, the contribution of rainwater $\mathrm{NO}_{3}-\mathrm{N}$ was not considered in modelling, however, it is significant in the area. It has been reported that an average concentration of 1.53 $\mathrm{mg} / \mathrm{l}(0-3.05 \mathrm{mg} / \mathrm{l}) \mathrm{NO}_{3}-\mathrm{N}$ was present in the rain water at Horton Plains which is at a close proximity to the study site (Gunawardene et al., 1998). In this context, a proper land management strategy to generate a balance between natural and agricultural land use system should be suggested along with proper management strategies to conserve the soils and steep slopes.

\section{Discussion and Conclusions}

Agriculture related environmental and water quality problems are spreading beyond the geographical boundaries of countries and have now become a global concern. The prediction of the catchment behaviour is essential for proper decision making in sustainable management of water resources. Majority of the catchments in the world are [data limited and, therefore, application of physically based complex models is practically difficult. In this situation, the simple catchment management tools such as MIR models are more effective since they can work with limited information while producing usable results.

The Upper Uma Oya catchment situated in the central hills of Sri Lanka is a classic example of the rapid land use conversion due to extensive agricultural practices. The catchment has undergone extensive land use/cover changes from natural cloud forests to plantation agriculture (tea) and then to vegetable and potato farming. In Sri Lanka, the catchment research is mostly confined to soil erosion related studies and the concern on agriculture related water pollution is seemingly neglected. Water quality data are mostly limited to few irregular measurements in major rivers or reservoirs. Lack of flow and nutrient time series of a considerable length hinder the application of hydrological and water quality models for catchment management.

The application of TOPCAT-NP model to the Upper Uma Oya catchment and its Sandatenna sub catchment produced good results in terms of flow and nutrient transport. The model output provides an indication towards the on-going catchment processes and the possible future changes.

Land use/cover scenario analysis provides an insight to the effect of land use/cover changes on flow and surfacewater quality. A proper land use/cover scenario analysis is possible only with distributed physically-based modelling. However, with the parameters that are sensitive to land use/cover and management practices in TOPCAT-NP, the model can potentially simulate stream flow and nutrients under various land use/cover options. The model results may be used as a guideline to identify the most suitable land use options and management criteria. However, the user should be well aware of the uncertainty associated with the parameters and its propagation to the final model output.

Finally, it should be emphasised that the catchment scale models should be simple and user friendly, while being comprehensive with multiple capabilities. They should appropriately address the issues prevailing in the catchments such as data limitations and errors in data, and also should be able to calibrate within the available information and in a reasonable computational time. The model should inspire an understanding of agriculture and hydrology and the threat of unmanaged land use changes on water resources. In this regard the MIR models may effectively be used in catchment planing and management. 


\section{References}

1. Addiscott, T.M. and Whitmore, A.P. (1991). "Simulation of solute leaching in soils with different permeabilities", Soil Use and Management, (7-2), 94-102.

2. Anthony, S., Quinn, P. and Lord, E. (1996). "Catchment scale modelling of nitrate leaching", Aspects of Applied Biology, (46), 23-32.

3. Beaulac, M.N. and Reckhow, K.H. (1982). "An examination of land use - Nutrient export relationships", Water Resources Bulletin, American Water Resources Association, (18-6), 1013-1024.

4. Brazier, R.E., Rowan, J.S., Anthony and S.G. and Quinn, PR (2001). “MIRSED” Towards a MIR approach to modelling hillslope soil erosion at the national Scale", Catena, (42), 59-79.

5. Greenwood, D.J. and Walker, A. (1990). "Modelling soil productivity and pollution in quantitative theory in soil productivity and environmental pollution", Proceeding of a Royal Society Discussion Meeting held on 7 and 8 March, 1990. Greenwood, D.J., Nye, P.H., and Walker, A. (Eds.), The Royal Society, London, 309-320.

6. Gunawardena, E.R.N., Rajapakshe, U., Nandasena, K.A. and Rosier, P.T.W. (1998). "Waterquality issues in uplands of Sri Lanka" in Proceedings of the Final Workshop, Gunasena, H.P.M., (Eds). University of Peradeniya - Oxford Forestry Institute link project, Sri Lanka - UK.

7. Heathwaite, A.L., Sharpley, A.N. and Gburek, W. (2000). "A conceptual approach for integrating phosphorus and nitrogen management at watershed scales", Journal of Environmental Quality, (29), 158-166.

8. Johnes, P., Moss, B. and Phillips, G. (1996). "The determination of total phosphorus concentrations in freshwaters from land use, stock headage and population data: Testing of a model use in conservation and water quality management", Freshwater Biology, (36), 451-473.

9. Johnes, P.J. (1996). "Evaluation and management of the impact of land use change on the nitrogen and phosphorus load delivered to surface waters: The export coefficient modelling approach", Journal of Hydrology, (183), 323-349.
10. Johnes, P.J. and O'Sullivan, P.E. (1989). "The natural history of Slapton Ley natural reserve XVIII. Nitrogen and phosphorus losses from the catchment - An export coefficient approach", Field Studies, (07), 285-309.

11. Leagreid M, Bookman, O.C., Kaarstad, O. (1999). "Agriculture, Fertilisers and the Environment", CABIPublishing, Wallingford, UK.

12. Needleman, B.A., Gburek, W.J., Sharpley, A.N. and Peterson. (2001). Environmental management of soil phosphorus: Modelling spatial variability in small watersheds", Soil Science Society of America Journal, (65), 1516-1522.

13. Quinn, P, Anthony, S. and Lord, E. (1999). "Basin Scale Nitrate Simulation Using a Minimum Information Requirement Approach", Water Quality Processes and Policy, Trudgill, S.T., Walling, D.E., Webb, B.W. (Eds), John Wiley \& Sons.

14. Quinn, P, Anthony, S.,Lord, E. and Turner, S. (1996). "Nitrate modelling for the UK: A minimum information requirement (MIR) model approach, Inter Celtic Symoosium, July 8-11, 1996, INRA Publication 46.

15. Quinn, P.F. and Bevan, K.J. (1993). "Spatial and temporal dynamics of the soil moisture dynamics, runoff, variable source areas and evapotranspiration for Plynlimon, Mid-Wales", Hydrological Processes, (7), 425-448.

16. Rajapakse, H.A. (1998). "Rationalising Land Use in the Uma Oya Catchment", Environmental \& Forest Conservation Division, Mahaweli Authority of Sri Lanka, Dam Site, Polgolla, 9p.

17. US Environmental Protection Agency (USEPA) (1984). "Report to congress: Non-point Source Pollution in the United States", USEPA, Washington D.C.

18. Vinten, A.J.A, and Smith, K.A. (1993). "Nitrogen cycling in agricultural soils in 'Nitrate: Processes, Patterns and Management", Eds: Burt, T.P., Heathwaite, A.L. and Trudgill, S.T., John Wiley and Sons. pp39-73.

19. Wickramagamage, P. (1988). "Large-scale deforestation for plantation agriculture in the hill country of Sri Lanka and its impacts", Hydrological Processes, (12), 2015-2028. 
20. Williams,J.R. (1995). The EPIC model in "Computer Models of Watershed Hydrology", Singh, V.P., (Eds:) Water Resource Publications, pp909-1000.

2I. Yatawara, S. (1996). "Upper MahaweliCatchment Sediment Discharge Measurements", Report No. 01, Environment and Forest Conservation Division, Mahaweli Authority of Sri Lanka, Dam site, Polgolla. 